\title{
Rare diseases caused by abnormal calcium sensing and signalling
}

\author{
Judit Tőke ${ }^{1} \cdot$ Gábor Czirják $^{2}$ Péter Enyedi ${ }^{2}$ Miklós Tóth $\mathbb{1}^{1}$
}

Received: 7 November 2020 / Accepted: 8 January 2021 / Published online: 2 February 2021

(c) The Author(s) 2021

\begin{abstract}
The calcium-sensing receptor (CaSR) provides the major mechanism for the detection of extracellular calcium concentration in several cell types, via the induction of G-protein-coupled signalling. Accordingly, CaSR plays a pivotal role in calcium homeostasis, and the $C a S R$ gene defects are related to diseases characterized by serum calcium level changes. Activating mutations of the CaSR gene cause enhanced sensitivity to extracellular calcium concentration resulting in autosomal dominant hypocalcemia or Bartter-syndrome type V. Inactivating CaSR gene mutations lead to resistance to extracellular calcium. In these cases, familial hypocalciuric hypercalcaemia (FHH1) or neonatal severe hyperparathyroidism (NSHPT) can develop. FHH2 and FHH3 are associated with mutations of genes of partner proteins of calcium signal transduction. The common polymorphisms of the CaSR gene have been reported not to affect the calcium homeostasis itself; however, they may be associated with the increased risk of malignancies.
\end{abstract}

Keywords Calcium-sensing receptor $\cdot$ Autosomal dominant hypocalcemia $\cdot$ Familial hypocalciuric hypercalcemia $\cdot$ Neonatal severe hyperparathyroidism

$\begin{array}{ll}\text { Abbreviations } \\ \text { ADH } & \text { Autosomal dominant hypocalcemia } \\ \text { ADIS } & \text { Agonist-driven insertional signalling } \\ \text { AP2 } & \text { Adaptor-related protein complex 2 } \\ \text { AP2 } \sigma & \begin{array}{l}\text { Adaptor-related protein complex 2, sigma } \\ \text { subunit }\end{array} \\ \text { CaCrCR } & \text { Calcium-to-creatinine clearance ratio } \\ \text { CaSR } & \text { Calcium-sensing receptor } \\ \text { FHH } & \text { Familial hypocalciuric hypercalcemia } \\ \text { Go } \alpha_{11} & \text { G-protein subunit } \alpha_{11} \\ \text { NSHPT } & \text { Neonatal severe hyperparathyroidism } \\ \text { PHPT } & \text { Primary hyperparathyroidism } \\ \text { PTH } & \text { Parathyroid hormone } \\ \text { ROMK } & \text { Renal outer-medullary K+ channel } \\ \text { SHPT } & \text { Secondary hyperparathyroidism }\end{array}$

Miklós Tóth

toth.miklos@med.semmelweis-univ.hu

1 Department of Internal Medicine and Oncology, Semmelweis University, Budapest, Hungary

2 Department of Physiology, Semmelweis University, Budapest, Hungary

\section{Physiological role of calcium-sensing receptor (CaSR) and its partner signalling proteins}

The CaSR is a member of family C of G-protein-coupled receptors. It was first cloned from bovine parathyroid cells in 1993 [1]. The human CaSR gene localizes on chromosome 3q13.3-21 and contains 8 exons, from which the first (1A and 1B) encodes alternatively spliced $5^{\prime}$-untranslated regions. The receptor protein is constituted of 1078 amino acids. It contains a large extracellular domain responsible for ligand binding and receptor dimerization, the transmembrane domain comprising seven transmembrane helices and a smaller intracellular domain, which transduces the evoked signal to the downstream intracellular partner proteins [2]. The receptor is highly expressed on the chief cells of the parathyroid glands and in the kidney; however, its expression has also been demonstrated in numerous other tissues and cell types [3].

The investigation of wild-type and mutated CaSR activity, complemented with the data of recent structural analyses of CaSR, provided deeper insight into the process of calcium-sensing and signalling. The activation of the dimerized receptor upon ligand binding causes conformational changes and coupling to $\mathrm{G} \alpha_{\mathrm{q} / 11}$ proteins. The main intracellular effector of this signal transduction is the cytoplasmic ionized calcium [4]. Proper expression on the 
cell surface is required for the normal function of the CaSR. The level of cell-surface expression is influenced by the balance of agonist-driven insertional signalling (ADIS) and the activity of adaptor-related protein complex 2 (AP2). ADIS provides anterograde trafficking of newly synthesised receptors to the plasma membrane after prolonged receptor activation. AP2 together with $\beta$-arrestin represent the key determinants of elimination from the cell surface as they facilitate clathrin-mediated endocytosis of CaSR [5].

\section{Inherited calcitropic diseases of the CaSR and its partner proteins}

The disturbances of extracellular calcium-sensing lead to pathological hypersensitivity or resistance to the extracellular calcium resulting in several disease states. The majority of these disorders is genetically determined by the mutations of the CaSR and its downstream partner signalling proteins. Some of them activate the CaSR resulting in hypersensitivity to extracellular calcium. This group of inherited hypocalcemic disorders involves the autosomal dominant hypocalcemia (ADH) (ADH1 and $\mathrm{ADH} 2)$ and Bartter-syndrome type V. Other genetic defects inactivate the calcium sensing pathway leading to resistance to extracellular ligands of CaSR. Heterozygous loss-offunction mutations lead to one of the three known subtypes of the usually symptomless familial hypocalciuric hypercalcaemia $(\mathrm{FHH})$, while germ-line homozygous inactivating $C a S R$ gene mutations are in the background of neonatal severe hyperparathyroidism (NSHPT).

\section{Diseases associated with increased sensitivity to the extracellular calcium concentration}

\section{Autosomal dominant hypocalcemia (ADH)}

Diseases with increased sensitivity to extracellular calcium are characterized by low extracellular calcium concentrations with inappropriately normal or suppressed parathyroid hormone $(\mathrm{PTH})$ secretion. The prototype of these conditions is the $\mathrm{ADH}$ representing the most common genetic cause of isolated hypoparathyroidism.

ADH1 (OMIM: 601198) accounts for $\approx 70 \%$ of ADH cases and are caused by heterozygous gain-of-function CaSR gene mutations [6]. It is considered as a rare disorder with prevalence 3.9 per 100,000 [7]. In the affected patients, the main laboratory findings are the subnormal or normal serum PTH level, together with inappropriately normal or elevated urinary calcium excretion despite low serum calcium. About half of the patients have mild hypocalcemic symptoms (neuromuscular irritability), and ectopic calcification (including basal ganglia) may also develop in about
$35 \%$ of patients [8]. Thiazide diuretics, calcium- and activated vitamin $\mathrm{D}$ supplementation can be offered to symptomatic individuals. The goal of the treatment is to maintain serum calcium level slightly below the normal range in order to avoid marked hypercalciuria, nephrocalcinosis, nephrolithiasis and renal impairment [9]. Recent studies aim to evaluate the safety and efficacy of calcilytic drugs in patients with ADH1. To date, there are clinical data with intravenously administered NPSP795, a negative allosteric modulator of the CaSR. Observations obtained from five patients with ADH1 confirmed the initial expectations that the short-acting NPSP795 can significantly and rapidly increase PTH secretion in a dose-dependent manner [10].

ADH2 (OMIM: 615361) is caused by activating heterozygous GNA11 gene mutations. GNA11 gene, located on chromosome 19p13.3, encodes the G-protein subunit $\alpha_{11}$ $\left(\mathrm{G} \alpha_{11}\right)$ protein, a major mediator of CaSR signalling. Eight heterozygous germ-line mutations of GNA11 gene have been reported to date. Patients with ADH2 have a milder biochemical phenotype than those with ADH1 [11]. In two kindreds, short stature was also observed $[12,13]$.

\section{Bartter-syndrome type V}

Bartter syndrome is characterized by deficient renal reabsorption of sodium and chloride, as well as hypokalemic metabolic alkalosis with secondary hyperaldosteronism. Genetic alterations of several ion transporters and channels have been associated with the pathogenesis of Bartter's syndrome, including activating mutations of the CaSR [14]. In Bartter-syndrome type V (OMIM: 601198), the constitutive activation of CaSR in the thick ascending limb inhibits the activity of the renal outer-medullary K channel and this results in renal salt wasting, hypocalcemia and hypomagnesemia as well as hyperreninaemic hyperaldosteronism and hypokalaemic alkalosis [15].

\section{Diseases associated with decreased sensitivity to the extracellular calcium concentration}

\section{Familial hypocalciuric hypercalcemia (FHH)}

Inactivating mutations in the proteins of calcium-sensing and signalling pathway cause FHH. FHH is a genetically heterozygous group of disorders inherited by autosomal dominant trait and characterized by mild, usually symptomless hypercalcemia and relative hypocalciuria [16]. At present, three types of FHH are known (FHH1, FHH2, FHH3). Their relative prevalances were estimated as 64:1:10, respectively [17].

FHH1 (OMIM: 145980) is caused by germ-line loss-offunction CaSR gene mutations on chromosome 3q21.1. This is the most common form of FHH comprising about 
$85 \%$ of all FHH cases. Over 300 CaSR gene mutations have been reported to date. Most of them are missense substitutions. The genetic defect usually affects the first 350 amino acid residues of the extracellular domain of the receptor. The altered structure of the extracellular domain is responsible for the decreased affinity to ionized calcium and impaired receptor dimerization. Previous studies have revealed that $50 \%$ of $C a S R$ gene mutations affect receptor trafficking and cell-surface expression [18]. Clinically, FHH1 is characterized by mild, non-progressive hypercalcemia, normal (in $80 \%$ of cases) or slightly elevated (in $20 \%$ of cases) serum PTH levels and hypocalciuria featured by low $(<0.01)$ calcium-to-creatinine clearance ratio (CaCrCR) [19]. The majority of patients are symptomless, though some with moderate-to-severe hypercalcemia may present with classical hypercalcemic symptoms (polyuriapolydipsia, fatigue, chronic pancreatitis, gallstones and chondrocalcinosis). In these latter rare cases, the affected patients may benefit from calcimimetic drug treatment $[20,21]$. FHH1 have been widely considered as a rare condition; however, according to a recent publication, the estimated frequency of FHH1 would be as high as the ageadjusted prevalence of classical primary hyperparathyroidism (PHPT): 74.1/100,000 for FHH1 vs. 48/100,000 for PHPT in adult males and 120/100,000 for PHPT in adult females [7, 22]. These findings strengthen previous recommendations, that in clinical practice, FHH1 should be differentiated from mild forms of PHPT as parathyroidectomy indicated for PHPT will not improve hypercalcemia in FHH patients. The first step to differentiate PHPT and FHH is the determination of CaCrCR. However, diagnosing patients with $\mathrm{CaCrCR}$ in the grey zone (0.01-0.02) is still challenging and needs genetic investigations [23].

Occasionally, neonates with heterozygous de novo or paternally inherited $C a S R$ gene mutation could present with severe clinical symptoms resembling to NSHPT (described below in detail). In these cases, the affected fetuses perceive the normal maternal calcium as low; therefore, secondary hyperparathyroidism (SHPT) will develop during intrauterine life [24]. Following delivery, as the maternal trigger to excess secretion of PTH is no longer present, the neonate will increase his/her calcium concentration to a higher value within a few days-weeks, and the rate of the PTH secretion will return to normal [25]. As a consequence, despite the severe laboratory signs and clinical symptoms resembling to NSHPT, this special, self-limiting form of hypocalciuric hypercalcemia should be classified as FHH1.

Genetic linkage analyses revealed that loss-of-function gene mutations of proteins involved in downstream CaSRsignalling pathway cause $\mathrm{FHH} 2$ and $\mathrm{FHH} 3$.

FHH2 (OMIM: 145981) is a rare autosomal dominant disorder caused by germ-line inactivating mutations of the
GNA11 gene, encoding the $\mathrm{G}_{\alpha 11}$ protein. To date, three different GNA11 gene mutations have been reported (Thr54Met, Leu135Gln, Ile200del). All patients presented with mild, symptomless hypercalcemia (<2.80 mmol/L) $[6,26]$. According to a recent study, the calcimimetic drug cinacalcet may have the potential to correct the hypercalcemia caused by the inactivating GNA11 Phe220Ser gene mutation, perhaps by enhancing the signalling process through the wild-type copy of $\mathrm{G}_{\alpha 11}$ protein [27].

In FHH3 (OMIM: 600740), germ-line mutations of AP2S1 gene located on chromosome $19 \mathrm{q} 13.3$ are present. AP2S1 gene encodes the sigma subunit of the adaptorrelated protein-2 (AP2 $\sigma)$, which has a fundamental role in clathrin-mediated CaSR endocytosis. The mutant AP2 $\sigma$ will lead to impaired $\mathrm{G}_{\alpha 11}-$ mediated CaSR signalling despite increased CaSR cell-surface expression [28, 29]. To resolve this paradox, a recent study has confirmed the previous hypothesis that CaSR does not only evoke an immediate response from the plasma membrane after extracellular ligand binding, but also has a sustained signalling from the endosomes, similarly to other GPCRs. Therefore, decreased endocytosis of the CaSR from the cell surface may have a consequent negative effect on endosome-mediated signalling [30]. Interestingly, all the reported AP2S1 gene mutations affect the $\mathrm{R} 15$ residue (Arg15Cys, Arg15His and Arg15Leu). Clinically, FHH3 patients usually have more severe hypercalcemia, hypermagnesemia as well as more marked hypocalciuria compared to those with FHH1. Furthermore, previous analyses revealed a genotype-phenotype correlation in the affected patients as those harbouring the Arg15Leu mutation are presented with the most severe hypercalcaemia among FHH3 patients. Low bone mineral density and cognitive disorders have also been reported in FHH3 [31].

\section{Neonatal severe hyperparathyroidism (NSHPT)}

NSHPT (OMIM: 239200) is caused by homozygous or compound heterozygous inactivating mutations of the CaSR gene. The clinical manifestation may be lifethreatening severe hypercalcemia $(>3.5 \mathrm{mmol} / \mathrm{L})$ with high serum PTH level, respiratory distress, hypotonia and severe hyperparathyroid bone disease with spontaneous bone fractures could develop in the affected neonates $[32,33]$. Parathyroidectomy is a reasonable therapeutic option. Medical treatment with intravenous pamidronate was reported as safe and effective rescue therapy for the management of preoperative severe hypercalcemia and life-threatening bone demineralisation [34, 35]. Cinacalcet, allosteric modulator of the CaSR also provides an alternative and safe treatment option as rapid normalization of elevated serum calcium and PTH level was reported in several cases [36-38]. There are two possible 
Table 1 Mutations of calcium-sensing receptor, its partner proteins and associated disorders

\begin{tabular}{|c|c|c|c|c|c|}
\hline Protein & Gene & Chromosomal location & Disorder & OMIM & Inheritance \\
\hline \multirow[t]{5}{*}{ CaSR } & CaSR & $3 \mathrm{q} 21.1$ & & & \\
\hline & Inactivating mutations & & FHH1 & 145980 & Autosomal dominant \\
\hline & & & NSHPT & 239200 & $\begin{array}{l}\text { Autosomal recessive or } \\
\text { dominant }\end{array}$ \\
\hline & Activating mutations & & $\mathrm{ADH} 1$ & 601198 & Autosomal dominant \\
\hline & & & Bartter-syndrome type V & 601198 & Autosomal dominant \\
\hline \multirow{3}{*}{$\begin{array}{l}\text { G-protein subunit } \\
\alpha 11\end{array}$} & GNA11 & $19 \mathrm{p} 13.3$ & & & \\
\hline & Inactivating mutations & & FHH2 & 145981 & autosomal dominant \\
\hline & Activating mutations & & $\mathrm{ADH} 2$ & 615361 & autosomal dominant \\
\hline \multirow[t]{2}{*}{$\mathrm{AP} 2 \sigma$ protein } & $A P 2 S 1$ & $19 \mathrm{q} 13.3$ & & & \\
\hline & Inactivating mutations & & FHH3 & 600740 & autosomal dominant \\
\hline
\end{tabular}

CaSR calcium-sensing receptor, $F H H$ familial hypocalciuric hypercalcemia, $N S H P T$ neonatal severe hyperparathyroidism, $A D H$ autosomal dominant hypocalcemia, $A P 2 \sigma$ adaptor-related protein complex 2, sigma 1 subunit

scenarios in which NSHPT could occur. (1) In neonates with homozygous CaSR mutation who are offspring of consanguineous parents harbouring the same inactivating CaSR mutation. (2) In neonates of parents, harbouring different inactivating mutations, compound heterozygous CaSR mutation could occur.

Mutations of the CaSR and its partner proteins, as well as the associated disorders, are presented in Table 1.

\section{Genetic counselling}

Genetic counselling and germ-line testing of the $C a S R$ gene are most frequently offered to adult patients diagnosed with asymptomatic mild hypercalcemia and hypocalciuria in whom there is a high suspicion of a hereditary disorder (familial aggregation of asymptomatic hypercalcemia, young age at the diagnosis) [39]. In clinical practice, the differential diagnosis between PHPT and FHH1 may be difficult. There are many overlaps between these two clinical entities, as PHPT could be present in an asymptomatic, mild form and hypocalciuria could be detected in some patients. On the contrary, $20 \%$ of patients with $\mathrm{FHH} 1$ have elevated serum PTH levels and a $\mathrm{CaCrCR}>0.01$. The proper differential diagnosis between FHH and PHPT is essential, as parathyroidectomy will not cease the hypercalcemia of FHH patients. Therefore, CaSR mutational screening would be useful in FHH1-suspected cases with atypical clinical presentation to avoid unnecessary parathyroidectomy.

The clinical presentation in $\mathrm{FHH} 2$ is usually similar to that of FHH1. Targeted genetic testing may be recommended for those patients in whom mutational analysis of CaSR gene detected normal sequences.
Table 2 Key statements for differential diagnosis and indications for genetic testing of FHH and PHPT

- The hallmark of FHH is a low $(<0.01) \mathrm{CaCrCR}$, but $\approx 20 \%$ of $\mathrm{FHH}$ patients have a $\mathrm{CaCrCR}>0.01$ [55].

- A replete vitamin D status is required for the accurate establishment of $\mathrm{CaCrCR}$ and the diagnosis of both FHH and PHPT.

- Renal impairment and thiazide use may result in false CaCrCR.

- The testing criteria for genetic diagnosis of $\mathrm{FHH}$ is $\mathrm{CaCrCR}<0.02$ [55].

- The recommended sequence of genetic testing follows the natural prevalence of various FHH subtypes, that is (1) CASR for FHH1, (2) AP2S1 for FHH3 and (3) GNA11 for FHH2.

- The presence of a parathyroid adenoma does not rule out the diagnosis of FHH.

FHH familial hypocalciuric hypercalcemia, $P H P T$ primary hyperparathyroidism, $\mathrm{CaCrCR}$ calcium-to-creatinine clearance ratio, $\mathrm{CaSR}$ calcium-sensing receptor

Concerning FHH3, mutation analysis of AP2S1 gene should be performed in those FHH patients who have marked hypermagnesemia, cognitive impairment and low bone mineral density.

In cases of the severe, life-threatening NSHPT occurring at birth or within the first 6 months of life, the diagnosis is usually established by the life-threatening clinical manifestations (severe hypercalcaemia, hypotonia, bone demineralization, fragility fractures and respiratory distress). The survival of the affected children depends on the early total parathyroidectomy. Prenatal genetic test or genetic test at birth are recommended in case of both parents proved to be carriers of CaSR mutations and/or present clinical signs of $\mathrm{FHH}$.

The key statements for differential diagnosis and indications for genetic testing of FHH and PHPT are presented in Table 2. 


\section{CaSR gene polymorphisms-clinical consequences}

Several CaSR polymorphisms have been identified in the intracellular domain of the CaSR gene. Among them, three clustered polymorphisms have been widely investigated in the past few decades (A986S (rs1801725), R990G (rs 1042636) and Q1011E (rs1801726)). The world-wide average allele frequencies of these genetic variants were reported as 0.1259 for A986S, 0.1456 for R990G and 0.9462 for Q1011E (https://gnomad.broadinstitute.org/).

These polymorphisms modify the three-dimensional structure of cytoplasmic tail of CaSR; therefore, it was presumed that they may influence the intracellular CaSR signalling. However, the data are conflicting regarding the functional consequences of these structural modifications. On the basis of in vitro functional characterisation of these genetic variants, it became widely accepted that they have no significant effect on CaSR function [40]. Furthermore, we and others have provided evidence that the effects of the CaSR gene mutations are not influenced by the presence of these variants [41, 42].

However, in the last few years, polymorphisms of the CaSR became the target of numerous oncological investigations as they may contribute to the development of cancerinduced hypercalcemia and consequently influence the clinical outcome of different malignant diseases. The independent effect of hypercalcemia on cancer development and prognosis is widely investigated in colorectal-, and breast cancers; however, it still remained undetermined whether the functional status of CaSR could be related to cancer outcomes in affected patients. Among the three above-clustered CaSR polymorphisms, A986S (rs1801725) and Q1011E (rs1801726) have been previously associated with higher serum calcium level $[43,44]$. On the contrary, R990G polymorphism seems to produce gain-of CaSR function and consequently associated with hypercalciuria in normal population and increased risk of renal stones in patients with PHPT $[45,46]$.

According to a recent meta-analysis, Q1011E (rs1801726) polymorphism has been associated with higher colorectal cancer risk in the distal colon site (OR: 1.418, 95\% C.I.: 1.017-1.977) while the presence of R990G (rs1042636) allele decreased the colorectal cancer risk both in proximal and distal colon. The most frequent polymorphism A986S (rs1801725) seems to have no effect on colorectal cancer risk in Caucasian population [47].

Elevated serum calcium has been coupled with poorer prognosis in breast cancer even without bone metastases, therefore polymorphisms previously predicted to decrease the sensitivity of the CaSR (A986S and Q1011E) are also in the focus in some oncological investigations concerning breast cancer. According to a recent paper, hypercalcemia in about
$20 \%$ of breast cancer patients without bone metastases is partly due to the presence of A986S polymorphism [48].

\section{Medical treatment with allosteric modulators of the CaSR}

Detailed knowledge about the structure and function of the CaSR promoted the development of compounds acting as allosteric modulators on the CaSR. Calcimimetic drugs have positive allosteric effects on the receptor ligand binding capacity, increasing the sensitivity of the CaSR to extracellular $\mathrm{Ca}^{2+}$ [49]. The prototype of this class of drugs is cinacalcet, which binds to the transmembrane domain of the CaSR. Its use is approved in patients with SHPT due to chronic end-stage kidney failure and in patients with PHPT for whom parathyroidectomy would be indicated on the bases of serum calcium levels, but in whom parathyroidectomy is clinically inappropriate or is contraindicated [50]. Concordant evidence suggests that calcimimetics also improve the clinical signs of symptomatic hypercalcemia in FHH patients. The recently approved etelcalcetide should be administered intravenously for the management of SHPT in adults on chronic haemodialysis. The binding site of etelcalcetide differs from that of cinacalcet, since etelcalcetide binds to the Cys 482 residue within the CaSR so-called venus flytrap module [51]. The net effect of calcimimetics is lowering PTH secretion and decreasing chief cell proliferation in the parathyroid glands [52]. According to some recent evidence, calcimimetics may also act as pharmacochaperones, since the enhancing effect on the trafficking of the mutant receptors to the cell surface has been proved [53].

In contrast, calcilytic molecules have negative allosteric effects on CaSR. These drugs were originally developed for the treatment of osteoporosis, taking advantage of the anabolic effect of elevated PTH concentration. However, animal models did not confirm this hypothesis, therefore calcilytics remain possible drug candidates for treating $\mathrm{ADH}$ patients in whom calcium and vitamin D supplementation is not sufficient for the correction of hypocalcemia or even worsens hypercalciuria leading to concurrent nephrocalcinosis, renal stone formation and renal impairment [54].

Funding Open Access funding provided by Semmelweis University.

\section{Compliance with ethical standards}

Conflict of interest The authors declare that they have no conflict of interest.

Ethical approval This article does not contain any studies with human participants or animals performed by any of the authors. 
Publisher's note Springer Nature remains neutral with regard to jurisdictional claims in published maps and institutional affiliations.

Open Access This article is licensed under a Creative Commons Attribution 4.0 International License, which permits use, sharing, adaptation, distribution and reproduction in any medium or format, as long as you give appropriate credit to the original author(s) and the source, provide a link to the Creative Commons license, and indicate if changes were made. The images or other third party material in this article are included in the article's Creative Commons license, unless indicated otherwise in a credit line to the material. If material is not included in the article's Creative Commons license and your intended use is not permitted by statutory regulation or exceeds the permitted use, you will need to obtain permission directly from the copyright holder. To view a copy of this license, visit http://creativecommons. org/licenses/by/4.0/.

\section{References}

1. E.M. Brown, G. Gamba, D. Riccardi, M. Lombardi, R. Butters, O. Kifor, A. Sun, M.A. Hediger, J. Lytton, S.C. Hebert, Cloning and characterization of an extracellular $\mathrm{ca}(2+)$-sensing receptor from bovine parathyroid. Nature 366, 575-580 (1993)

2. J.E. Garrett, I.V. Capuano, L.G. Hammerland, B.C. Hung, E.M. Brown, S.C. Hebert, E.F. Nemeth, F. Fuller, Molecular cloning and functional expression of human parathyroid calcium receptor cdnas. J. Biol. Chem. 270, 12919-12925 (1995)

3. F.M. Hannan, E. Kallay, W. Chang, M.L. Brandi, R.V. Thakker, The calcium-sensing receptor in physiology and in calcitropic and noncalcitropic diseases. Nat. Rev. Endocrinol. 15, 33-51 (2018)

4. E.M. Brown, Four-parameter model of the sigmoidal relationship between parathyroid hormone release and extracellular calcium concentration in normal and abnormal parathyroid tissue. J. Clin. Endocrinol. Metab. 56, 572-581 (1983)

5. M.P. Grant, A. Stepanchick, A. Cavanaugh, G.E. Breitwieser, Agonist-driven maturation and plasma membrane insertion of calcium-sensing receptors dynamically control signal amplitude. Sci. Signal. 4, ra78 (2011)

6. M.A. Nesbit, F.M. Hannan, S.A. Howles, V.N. Babinsky, R.A. Head, T. Cranston, N. Rust, M.R. Hobbs, H. Heath 3rd, R.V. Thakker, Mutations affecting g-protein subunit alpha11 in hypercalcemia and hypocalcemia. N. Engl. J. Med. 368, 2476-2486 (2013)

7. R. Dershem, C.M. Gorvin, R.P.R. Metpally, S. Krishnamurthy, D. T. Smelser, F.M. Hannan, D.J. Carey, R.V. Thakker, G.E. Breitwieser, Familial hypocalciuric hypercalcemia type 1 and autosomal-dominant hypocalcemia type 1: Prevalence in a large healthcare population. Am. J. Hum. Genet. 106, 734-747 (2020)

8. F. Raue, J. Pichl, H.G. Dörr, D. Schnabel, P. Heidemann, G. Hammersen, C. Jaursch-Hancke, R. Santen, C. Schöfl, M. Wabitsch, C. Haag, E. Schulze, K. Frank-Raue, Activating mutations in the calcium-sensing receptor: genetic and clinical spectrum in 25 patients with autosomal dominant hypocalcaemia -a German survey. Clin. Endocrinol. 75, 760-765 (2011)

9. K.L. Roszko, R.D. Bi, M. Mannstadt, Autosomal dominant hypocalcemia (hypoparathyroidism) types 1 and 2. Front. Physiol. 7, 458 (2016)

10. M.S. Roberts, R.I. Gafni, B. Brillante, L.C. Guthrie, J. Streit, D. Gash, J. Gelb, E. Krusinska, S.C. Brennan, M. Schepelmann, D. Riccardi, M.E. Bin Khayat, D.T. Ward, E.F. Nemeth, R. Rosskamp, M.T. Collins, Treatment of autosomal dominant hypocalcemia type 1 with the calcilytic npsp795 (shp635). J. Bone Miner. Res. 34, 1609-1618 (2019)
11. C.M. Gorvin, V.J. Stokes, H. Boon, T. Cranston, A.K. Glück, S. Bahl, T. Homfray, T. Aung, B. Shine, K.E. Lines, F.M. Hannan, R.V. Thakker, Activating mutations of the g-protein subunit $\alpha 11$ interdomain interface cause autosomal dominant hypocalcemia type 2. J. Clin. Endocrinol. Metab. 105, 952-963 (2020)

12. D. Li, E.E. Opas, F. Tuluc, D.L. Metzger, C. Hou, H. Hakonarson, M.A. Levine, Autosomal dominant hypoparathyroidism caused by germline mutation in gna11: phenotypic and molecular characterization. J. Clin. Endocrinol. Metab. 99, E1774-1783 (2014)

13. S. Tenhola, R. Voutilainen, M. Reyes, S. Toiviainen-Salo, H. Jüppner, O. Mäkitie, Impaired growth and intracranial calcifications in autosomal dominant hypocalcemia caused by a gna11 mutation. Eur. J. Endocrinol. 175, 211-218 (2016)

14. T.D.S. Cunha, I.P. Heilberg, Bartter syndrome: causes, diagnosis, and treatment. Int. J. Nephrol. Renovasc. Dis. 11, 291-301 (2018)

15. S. Watanabe, S. Fukumoto, H. Chang, Y. Takeuchi, Y. Hasegawa, R. Okazaki, N. Chikatsu, T. Fujita, Association between activating mutations of calcium-sensing receptor and bartter's syndrome. Lancet 360, 692-694 (2002)

16. M.R. Pollak, E.M. Brown, Y.H. Chou, S.C. Hebert, S.J. Marx, B. Steinmann, T. Levi, C.E. Seidman, J.G. Seidman, Mutations in the human $\mathrm{ca}(2+)$-sensing receptor gene cause familial hypocalciuric hypercalcemia and neonatal severe hyperparathyroidism. Cell 75, 1297-1303 (1993)

17. S.J. Marx, D. Goltzman, Evolution of our understanding of the hyperparathyroid syndromes: a historical perspective. J. Bone Miner. Res. 34, 22-37 (2019)

18. Y. Huang, G.E. Breitwieser, Rescue of calcium-sensing receptor mutants by allosteric modulators reveals a conformational checkpoint in receptor biogenesis. J. Biol. Chem. 282, 9517-9525 (2007)

19. J.Y. Lee, D.M. Shoback, Familial hypocalciuric hypercalcemia and related disorders. Best. Pract. Res. Clin. Endocrinol. Metab. 32, 609-619 (2018)

20. U.S. Alon, R.G. VandeVoorde, Beneficial effect of cinacalcet in a child with familial hypocalciuric hypercalcemia. Pediatr. Nephrol. 25, 1747-1750 (2010)

21. H.J. Timmers, M. Karperien, N.A. Hamdy, H. de Boer, A.R. Hermus, Normalization of serum calcium by cinacalcet in a patient with hypercalcaemia due to a de novo inactivating mutation of the calcium-sensing receptor. J. Intern. Med. 260, 177-182 (2006)

22. M.W. Yeh, P.H.G. Ituarte, H.C. Zhou, S. Nishimoto, I.-L. Amy Liu, A. Harari, P.I. Haigh, A.L. Adams, Incidence and prevalence of primary hyperparathyroidism in a racially mixed population. $\mathrm{J}$. Clin. Endocrinol. Metab. 98, 1122-1129 (2013)

23. S.E. Christensen, P.H. Nissen, P. Vestergaard, L. Mosekilde, Familial hypocalciuric hypercalcaemia: a review. Curr. Opin. Endocrinol. Diabetes Obes. 18, 359-370 (2011)

24. O.I. Egbuna, E.M. Brown, Hypercalcaemic and hypocalcaemic conditions due to calcium-sensing receptor mutations. Best. Pract. Res. Clin. Rheumatol. 22, 129-148 (2008)

25. M. Glaudo, S. Letz, M. Quinkler, U. Bogner, U. Elbelt, C.J. Strasburger, D. Schnabel, E. Lankes, S. Scheel, J. Feldkamp, C. Haag, E. Schulze, K. Frank-Raue, F. Raue, B. Mayr, C. Schofl, Heterozygous inactivating casr mutations causing neonatal hyperparathyroidism: function, inheritance and phenotype. Eur. J. Endocrinol. 175, 421-431 (2016)

26. C.M. Gorvin, T. Cranston, F.M. Hannan, N. Rust, A. Qureshi, M. A. Nesbit, R.V. Thakker, A g-protein subunit- $\alpha 11$ loss-of-function mutation, thr54met, causes familial hypocalciuric hypercalcemia type 2 (fhh2). J. Bone Miner. Res. 31, 1200-1206 (2016)

27. C.M. Gorvin, F.M. Hannan, T. Cranston, H. Valta, O. Makitie, C. Schalin-Jantti, R.V. Thakker, Cinacalcet rectifies hypercalcemia in a patient with familial hypocalciuric hypercalcemia type 2 (fhh2) 
caused by a germline loss-of-function $\mathrm{g} \alpha(11)$ mutation. J. Bone Miner. Res. 33, 32-41 (2018)

28. F.M. Hannan, V.N. Babinsky, R.V. Thakker, Disorders of the calcium-sensing receptor and partner proteins: Insights into the molecular basis of calcium homeostasis. J. Mol. Endocrinol. 57, R127-142 (2016)

29. M.A. Nesbit, F.M. Hannan, S.A. Howles, A.A. Reed, T. Cranston, C.E. Thakker, L. Gregory, A.J. Rimmer, N. Rust, U. Graham, P.J. Morrison, S.J. Hunter, M.P. Whyte, G. McVean, D. Buck, R.V. Thakker, Mutations in ap2s1 cause familial hypocalciuric hypercalcemia type 3. Nat. Genet. 45, 93-97 (2013)

30. C.M. Gorvin, A. Rogers, B. Hastoy, A.I. Tarasov, M. Frost, S. Sposini, A. Inoue, M.P. Whyte, P. Rorsman, A.C. Hanyaloglu, G. E. Breitwieser, R.V. Thakker, Ap2 $\sigma$ mutations impair calciumsensing receptor trafficking and signaling, and show an endosomal pathway to spatially direct g-protein selectivity. Cell Rep. 22, 1054-1066 (2018)

31. F.M. Hannan, S.A. Howles, A. Rogers, T. Cranston, C.M. Gorvin, V.N. Babinsky, A.A. Reed, C.E. Thakker, D. Bockenhauer, R.S. Brown, J.M. Connell, J. Cook, K. Darzy, S. Ehtisham, U. Graham, T. Hulse, S.J. Hunter, L. Izatt, D. Kumar, M.J. McKenna, J.A. McKnight, P.J. Morrison, M.Z. Mughal, D. O’Halloran, S.H. Pearce, M.E. Porteous, M. Rahman, T. Richardson, R. Robinson, I. Scheers, H. Siddique, W.G. Van't Hoff, T. Wang, M.P. Whyte, M. A. Nesbit, R.V: Thakker, Adaptor protein-2 sigma subunit mutations causing familial hypocalciuric hypercalcaemia type 3 (fhh3) demonstrate genotype-phenotype correlations, codon bias and dominant-negative effects. Hum. Mol. Genet. 24, 5079-5092 (2015)

32. I.R. Gunn, D. Gaffney, Clinical and laboratory features of calcium-sensing receptor disorders: a systematic review. Ann. Clin. Biochem. 41, 441-458 (2004)

33. S.J. Marx, N. Sinaii, Neonatal severe hyperparathyroidism: novel insights from calcium, pth, and the casr gene. J. Clin. Endocrinol. Metab. 105, 1061-1078 (2020)

34. L. Fox, J. Sadowsky, K.P. Pringle, A. Kidd, J. Murdoch, D.E. Cole, E. Wiltshire, Neonatal hyperparathyroidism and pamidronate therapy in an extremely premature infant. Pediatrics 120, e1350-1354 (2007)

35. S. Waller, T. Kurzawinski, L. Spitz, R. Thakker, T. Cranston, S. Pearce, T. Cheetham, W.G. van't Hoff, Neonatal severe hyperparathyroidism: genotype/phenotype correlation and the use of pamidronate as rescue therapy. Eur. J. Pediatr. 163, 589-594 (2004)

36. A.W. Gannon, H.M. Monk, M.A. Levine, Cinacalcet monotherapy in neonatal severe hyperparathyroidism: a case study and review. J. Clin. Endocrinol. Metab. 99, 7-11 (2014)

37. C.M. Reh, G.N. Hendy, D.E. Cole, D.D. Jeandron, Neonatal hyperparathyroidism with a heterozygous calcium-sensing receptor (casr) r185q mutation: clinical benefit from cinacalcet. J. Clin. Endocrinol. Metab. 96, E707-712 (2011)

38. X. Sun, L. Huang, J. Wu, Y. Tao, F. Yang, Novel homozygous inactivating mutation of the calcium-sensing receptor gene in neonatal severe hyperparathyroidism responding to cinacalcet therapy: a case report and literature review. Medicine 97, e13128 (2018)

39. S. Khairi, J. Osborne, M.F. Jacobs, G.T. Clines, B.S. Miller, D.T. Hughes, T. Else, Outcome of clinical genetic testing in patients with features suggestive for hereditary predisposition to pthmediated hypercalcemia. Horm. Cancer 11, 250-255 (2020)

40. B. Harding, A.J. Curley, F.M. Hannan, P.T. Christie, M.R. Bowl, J.J. Turner, M. Barber, I. Gillham-Nasenya, G. Hampson, T.D. Spector, R.V. Thakker, Functional characterization of calcium sensing receptor polymorphisms and absence of association with indices of calcium homeostasis and bone mineral density. Clin. Endocrinol. 65, 598-605 (2006)

41. J. Toke, G. Czirjak, A. Patocs, B. Enyedi, P. Gergics, V. Csakvary, P. Enyedi, M. Toth, Neonatal severe hyperparathyroidism associated with a novel de novo heterozygous r551k inactivating mutation and a heterozygous a986s polymorphism of the calciumsensing receptor gene. Clin. Endocrinol. 67, 385-392 (2007)

42. C. Leech, P. Lohse, V. Stanojevic, A. Lechner, B. Göke, C. Spitzweg, Identification of a novel inactivating r465q mutation of the calcium-sensing receptor. Biochem. Biophys. Res. Commun. 342, 996-1002 (2006)

43. A. Scillitani, V. Guarnieri, C. Battista, S. De Geronimo, L.A. Muscarella, I. Chiodini, M. Cignarelli, S. Minisola, F. Bertoldo, C.M. Francucci, N. Malavolta, A. Piovesan, M.L. Mascia, S. Muscarella, G.N. Hendy, L. D’Agruma, D.E. Cole, Primary hyperparathyroidism and the presence of kidney stones are associated with different haplotypes of the calcium-sensing receptor. J. Clin. Endocrinol. Metab. 92, 277-283 (2007)

44. D.E. Cole, V.D. Peltekova, L.A. Rubin, G.A. Hawker, R. Vieth, C.C. Liew, D.M. Hwang, J. Evrovski, G.N. Hendy, A986s polymorphism of the calcium-sensing receptor and circulating calcium concentrations. Lancet 353, 112-115 (1999)

45. G. Vezzoli, A. Terranegra, T. Arcidiacono, R. Biasion, D. Coviello, M.L. Syren, V. Paloschi, S. Giannini, G. Mignogna, A. Rubinacci, A. Ferraretto, D. Cusi, G. Bianchi, L. Soldati, R990g polymorphism of calcium-sensing receptor does produce a gainof-function and predispose to primary hypercalciuria. Kidney Int. 71, 1155-1162 (2007)

46. A. García-Castaño, L. Madariaga, G. Pérez de Nanclares, G. Ariceta, S. Gaztambide, L: Castaño, Novel mutations associated with inherited human calcium-sensing receptor disorders: a clinical genetic study. Eur. J. Endocrinol. 180, 59-70 (2019)

47. S. Jeong, J.H. Kim, M.G. Kim, N. Han, I.W. Kim, T. Kim, J.M. Oh, Genetic polymorphisms of casr and cancer risk: Evidence from meta-analysis and huge review. Onco Targets Ther. 9, 655-669 (2016)

48. L. Wang, S.E. Widatalla, D.S. Whalen, J. Ochieng, A.M. Sakwe, Association of calcium sensing receptor polymorphisms at rs 1801725 with circulating calcium in breast cancer patients. BMC Cancer 17, 511 (2017)

49. E.F. Nemeth, Calcimimetic and calcilytic drugs: just for parathyroid cells? Cell Calcium 35, 283-289 (2004)

50. A. Khan, J. Bilezikian, H. Bone, A. Gurevich, P. Lakatos, W. Misiorowski, L. Rozhinskaya, M.L. Trotman, M. Toth, Cinacalcet normalizes serum calcium in a double-blind randomized, placebocontrolled study in patients with primary hyperparathyroidism with contraindications to surgery. Eur. J. Endocrinol. 172, 527-535 (2015)

51. S.T. Alexander, T. Hunter, S. Walter, J. Dong, D. Maclean, A. Baruch, R. Subramanian, J.E. Tomlinson, Critical cysteine residues in both the calcium-sensing receptor and the allosteric activator amg 416 underlie the mechanism of action. Mol. Pharmacol. 88, 853-865 (2015)

52. N. Hamano, H. Komaba, M. Fukagawa, Etelcalcetide for the treatment of secondary hyperparathyroidism. Expert Opin. Pharmacother. 18, 529-534 (2017)

53. G.E. Breitwieser, Pharmacoperones and the calcium sensing receptor: exogenous and endogenous regulators. Pharmacol. Res. 83, 30-37 (2014)

54. F.M. Hannan, M.K. Olesen, R.V. Thakker, Calcimimetic and calcilytic therapies for inherited disorders of the calcium-sensing receptor signalling pathway. Br. J. Pharmacol. 175, 4083-4094 (2018)

55. S. Mariathasan, K.A. Andrews, E. Thompson, B.G. Challis, S. Wilcox, H. Pierce, J. Hale, S. Spiden, G. Fuller, H.L. Simpson, B. Fish, P. Jani, I. Seetho, R. Armstrong, L. Izatt, M. Joshi, A. Velusamy, S.M. Park, R.T. Casey, Genetic testing for hereditary hyperparathyroidism and familial hypocalciuric hypercalcaemia in a large uk cohort. Clin. Endocrinol. 93, 409-418 (2020) 